\title{
Crystallisation of meaning as a technique for forming intercultural communicative competence within the real-virtual dichotomy
}

\author{
Inna Petrovna Cherkasova ${ }^{1}$, Tatiana Nikolaevna Reva $^{1}$, Nadezhda Valerievna Palanchuk ${ }^{2}$, \\ Svetlana Aleksandrovna Pashneva ${ }^{3}$, and Margarita Anatolievna Kozhevnikova ${ }^{4}$ \\ ${ }^{1}$ K.G. Razumovsky Moscow State University of Technologies and Management (the First Cossack \\ University), Faculty of Social and Humanitarian Technologies, Moscow, Russia \\ ${ }^{2}$ Russian University of Transport (MIIT), Department of Russian and Foreign Languages, Moscow, \\ Russia \\ ${ }^{3}$ Kursk State University, Faculty of Foreign Languages, Kursk, Russia \\ ${ }^{4}$ Military University of the Ministry of Defence of the Russian Federation, Department No. 9 (Foreign \\ languages), Moscow, Russia
}

\begin{abstract}
The article explores the formation of intercultural communicative competence within the framework of the "real - virtual" dichotomy. The principal instrument of formation is the meaning crystallisation technique based on the material of media discourse as well as computer and art-specific types of discourse. The discourse is viewed as a complex structural and semantic formation, an axiological system that has a definite functional perspective; it represents itself as a domain for realisation of specific values or their facets depending on the situational context, as actualisation of interaction between textual structures and extra-linguistic factors. The discourse is based on the system of concepts relevant for intercultural communication. The concept is a totality of meanings representing an axiological category that is important within the space of a particular discourse. Language is social and pragmatic in its core; therefore, the substantive and semantic aspects of linguistic units are connected with socio-cultural factors, the ways of vision and comprehension of objects. The relevance of research in this sphere is determined by: 1) the growing interest in the problems of dialogue of cultures and intercultural communication; 2) the attention of researchers to the structural and semantic organisation of discursive spheres; 3) the specificity of communication types that have a significant impact on the social worldview; 4) the importance of identification and formation of axiological benchmarks in the society; 5) the features related with extension of the virtual interaction sphere. Crystallisation is principally a process in which interpretation is used to trace the semantic content of words that, in the context of thinking or art, becomes independent of the norm fixed by dictionary definitions. The study of crystallisation processes involves the analysis of concepts in terms of dialogue of cultures. Concepts are verbalised in accordance with the nature and uniqueness of material,
\end{abstract}

*Corresponding author: inna cherkasova@mail.ru 
spiritual and social culture, in close connection with linguistic and pragmatic components. The research results can be used in courses on foreign language teaching methodology, theory and practice of intercultural communication, discourse theory, stylistics, and interpretation of texts.

Keywords: discourse, concept, communication, text, axiology, structure

\section{Introduction}

The $21^{\text {st }}$-century scientific research is characterised by the urge towards comprehensive consideration of phenomena from the point of view of interaction of language with reality. In this regard, researchers are increasingly turning to the study of intercultural communication - a broad field focusing on the relationship between the individual, his experience and communicative activity. The intercultural communication phenomenon is viewed as a complex phenomenon focused on the problems of comprehension and mutual understanding that underlie not only the success of communication, but also the specifics of axiological impact on the recipients as well as the formation of their axiological system. Litvinov notes that communication is "not just a conversation; it is a talk (dialogue = dia logos) in the course of which not only people communicate, but - through people and human individuals' interaction - entire languages, mentality patterns, ideologies, cultural contents and cultures at large" [1]; it is an event in the lifeworld "the content of which relates to the world of culture" [1]. Communication at the present stage of social development is largely transferred to the virtual space of media discourse, computer forums and chat rooms that influence the formation of the social worldview and the dialogue of cultures.

The formation of intercultural communicative competence is the main goal of foreign language teaching at higher educational institutions. The relevance of research in this sphere is determined by: 1) the growing interest in the problems of dialogue of cultures and intercultural communication; 2) the attention of researchers to the structural and semantic organisation of discursive spheres; 3 ) the specificity of communication types that have a significant impact on the social worldview; 4) the importance of identification and formation of axiological benchmarks in the society; 5) the features related with extension of the virtual interaction sphere.

Considering the processes of intercultural communicative competence formation, we simultaneously enter the space of hermeneutic experience that takes into account the presence of reflexion, reflexive reality, comprehension aspects and multifacetedness of an object. The semantic and cognitive levels of understanding lose their importance and give priority to the process of de-objectification within the dialogue of cultures. Undoubtedly, the process of understanding is profoundly subjective; in this regard, requires creative approaches to study at the university $[2,3,4,5,6,7,8,9]$, a multitude of interpretations and interpreting meanings are directly related with individual features of learners and researchers, their level of development, the horizon of their reflective reality.

In recent years, the problems involving representation of national values have become increasingly relevant, with regard for the processes of globalisation. It is value priorities within the framework of the modern anthropocentric paradigm that allow structuring a dialogue in a monocultural and intercultural space; therefore, research work in this area is extremely important and valuable. 


\section{Methods}

The formation of intercultural communicative competence takes place in the process of acquiring knowledge, skills and abilities through a dialogue within the dichotomy "real virtual". The basis of a dialogue is represented by the text in a broad sense and all of its various manifestations (verbal, written, creolised, and virtual, etc.). The result of a "dialogue" is comprehension. Various issues of comprehension have been broadly explored by G. Bogin who believes that "understanding is the assimilation by the mind of what is present or is given implicitly" [10]. The recipient builds his own imaginative world in the process of reading. Meanings, according to the quoted author, exist only in reflexion, in man's interacting with the text, or are experienced inwardly by the recipient.

In this connection, it seems important to take into account the communicative personality types that are involved in the communicative act "person - text", as proposed by V.Karasik [11]. Since every individual perceives the world and lives through it in his own way, the reflective reality of any person is unique. Therefore, understanding of the same text by different recipients is inevitably different. In this connection, G. Bogin talks about the interaction of aspects of a phenomenon to be understood and the inevitable multifacetedness thereof [10].

The formation of intercultural communicative competence seems possible within the framework of the hermeneutic experience, methods and techniques proposed by the Tver (G.Bogin et al.) and Pyatigorsk (V.Litvinov et al.) hermeneutic schools and with regard for the philosophical reflections on the substance of the word (E.Cassirer, G.Gadamer, M. Heidegger et al.).

Baranov distinguishes the following models of text comprehension: constructive model, hermeneutic model, functional-semiotic model, contradiction-synergy model and configuration model [5]. At the same time, any type of text imposes its own specific requirements on studying.

Of special interest and significance are: G. Gadamer's method of "hermeneutic circle" [12], methods and schemes of the reader's actions in terms of G.Bogin's treatment of meaning [10] and R. Barthes's method of textual analysis [13].

The hermeneutic circle method is based on the concept of infinite cognition of the text, where the meaning comprehension process takes place circle-wise, or rather, spiral-wise: the progression is from the meaning of the entire text to its details or to other texts' means of expression (in case of research in intertextual space), and then in the opposite direction, towards the whole. Thus, the comprehension level increases considerably at each turn of the spiral.

At the heart of G. Bogin's methodology is the idea of identifying textual meanings and, on their basis, formation and research of textual meta-meanings and meta-relationships. According to G. Bogin, comprehension has two aspects: substantive and processual. The scientist distinguishes the taxonomy of processual and epiphenomenal comprehension. When this taxonomy is applied with respect to a text, then, according to G.Bogin, the following hierarchically arranged comprehension types can be revealed: 1) semantic ("decoding" of text units); 2) cognitive (assimilating the content of perceived information); 3) notional (de-objectification of ideal reality) [10].

G.Bogin distinguishes several aspects ("facets") of the phenomenon being understood within the framework of his theory. When the text is being comprehended, the textual content facets and the recipient's experience facets (reflective reality) come into complex interaction, following which the object being contemplated is outlined as such. Since the 
human activity changes and gets enriched historically, the relevance of some particular facet may be lost over time, while the importance of some other facet - actualised.

Reflexion acts as a link between reflective reality and meaningfulness of the text. As a result, the conceived image gains the signs of earlier assimilated situations, on the one hand, and the treatment of one's old experience changes, on the other hand. These changes provide one with new experience underlying comprehension, owing to which the act of textual understanding leads to new knowledge [10].

R. Barthes proposes to dissect the text into short segments (a phrase, several phrases), to trace the connotative meanings of lexical units and to "unfold the text" stepwise. Thus, the analysis coincides with the actual reading process [13].

Special techniques of understanding are involved in the comprehension process. Bogin lists the following as the comprehension techniques: breaking the hermeneutic circle, deep penetration into the essence, decoding, build-up of meanings, conjunction, etc. [10].

\section{$3 \quad$ Results}

Special features are characteristic of texts within pluralistic space of the polylogos. V.Litvinov treats language as a pluralistic concept existing due to the plurality of languages [1] that function for verbalisation of different worldview forms and different concepts of world structuring. In addition, it is necessary to mention intercultural differences in the social sphere, that include diverse forms of social stratification, status differences, discrepancies in used code systems. From the social point of view, language acts as a set of sociolects engendered by the culture and the country specifics.

Intercultural dialogue represents the forms of existence, while reflexion makes it possible to comprehend the consciousness substantialisation forms. Reflexion, as a link between experience and concrete axiogenic situation represented in the text, brings together the experience of memory in semanticising comprehension, the experience of knowledge in cognitive comprehension and the meaningful experience in de-objectifying comprehension, and thus sets the reference points in the notional world of discourse.

The phenomenon of crystallisation is not sufficiently studied in modern linguistics and teaching methodology. Nevertheless, it should be noted that the term is used in scientific papers (I. Cherkasova, A.Baranov, I. Vorobei, V. Karasik, M.Semenov, M.Tkachev, A.Emelianova, K.Redkozubova). The process of crystallisation is based on such concepts as ideation and meaning. Zvegintsev argues that people exchange not words, but thoughts, using words as "the means for realisation of communication activity". It is the thought that is initial, subordinating language to itself. Sequences of words and their grammatical structure have a certain value only as components of the semantic whole [14]. The role of thinking in the human existence process was repeatedly emphasised by G.Shchedrovitsky: "I am a vessel with living, self-developing thinking; I am a thinking ideation, its hypostasis and materialisation, the organism of thought. And nothing else. This is how I view myself and how I treat myself' [15]. It is possible to argue with the formulation, but the unconditional primacy of ideation in the process of cognition is obvious.

V.Karasik proposes to treat the process of crystallisation as accumulation of "experienced, culturally significant knowledge about the world in the content of linguistic units and the conscience of a linguistic personality" [16]. Based on the above, crystallisation is defined, within the framework of the present paper, as a build-up process in respect of semantic content of the words which become independent of the norm fixed by dictionary definitions in the context of thinking or in art. This process makes it possible not only to identify the basic meanings, but also to trace the process of their interaction and 
sometimes - supersedure of some meanings with other ones. Comprehension technique may include the study of lexeme usage concordance in the text, as well as the research of the meaning crystallisation process $[17,18,19,20]$. Meanings are "scattered in textual space" (G.Bogin, I.Vorobey), and it can be asserted that the process of understanding is connected with the decoding and de-objectification processes and the crystallisation process.

Talking of crystallisation of meaning, one cannot ignore E. Cassirer's scientific contribution to the development of this problem. Cassirer viewed man as being simultaneously in several media: organic (natural-biological), perceptual (perception space), pragmatist (practice medium), abstract, but most importantly - symbolic, based on language, myth, art and religion. Man is animal symbolicum [21] A symbolic object of culture, in its turn, is characterised by three dimensions: physical presence, substantive representation and personal expression [21]. Space, in general, acquires sense and form (Fügung) through the meaning (Sinnordnung) in the context of which it is structured, i.e. mythical, aesthetic, theoretical and other domain [21].

The expressed item (cultural object) is to be perceived; perception occurs as follows: several points, Grundeinheiten, are fixed in the flow of phenomena and serve as focal points of orientation. The remaining phenomena relate to these "centres"; the circles of objectively cognisable reality diverge from here. Spaces are numerous since they are a form of orderliness for consciousness. Perception of a meaning is not the same as perception of a thing. In order to understand some poetic content, one needs to shift himself to additional dimensions of existence - to symbolic space, according to E. Cassirer. It is there that strange creatures like Gefühle can dwell - who have a longing for their Gefühlinnen or anything else that is equally bizarre, like in Rilke's poems. But perception of meaning also rests on some "centre", Grundeinheit, "focus", so that the circles of being-realised content "diverge" from it.

The word does not serve as a characterisation to reflect the world - it plays the role of crystallisation point in the diversity of representations. The symbolism of the word lies in the fact that it links the actual and the transcendental. All questions about the meaning refer to the transcendent: "The word wants to mean". Language is not, therefore, a system of characters for E.Cassirer, but the medium of man's spiritual existence [22]. We "live in meanings" of this medium; it is clear that the subject content of a word is not its origination, but its goal. The subject appears as a result of energy of the word, rather than underpins it.

Naturally, "crystallisation" in the philosophical system of Cassirer and "crystallisation" in the hermeneutic system of comprehension, despite the unconditional relationship of these notions, represent different things. According to Cassirer, it is rather a self-organising structure. In comprehending a text (a concept), this is basically a process of tracing, with the help of interpretation, of the semantic content of words which become independent of the norm fixed by dictionary definitions in the context of thinking or artistic environment. This process involves a number of stages that can be represented step by step as follows: 1) analysing the text in general; 2) identifying the contexts in which some key word is presented or through which the analysed concept is represented; 3) analysing selected passages in terms of lexical realisation; 4) analysing selected passages in terms of notional content; 5) comparison of meanings revealed in the course of analysis of all contexts; 6) consideration of semantic synthesis processes; 7) definition of meta-meanings characterising the studied concept; 8) analysis of interaction of meta-meanings within the concepts and the text; 9) formation of the textual space (spheres: media, computer (forum, chat, etc.), art, etc.). 
The study of the crystallisation process allows not only to identify the basic meanings, but also to trace the process of their interaction and mutual influence, and sometimes supersedure of some meanings by others, with incremental birth of linguocultural "fabric" of the concept in different types of discourse, the most important of which, for learning purposes, are media discourse, computer discourse and art discourse. The word semantics in a discourse is determined by the context which enhances or even changes the word meaning to the opposite. Keywords are at the centre of fundamental concepts and undoubtedly become an important way to express the focal points of the author's worldview; they have a function of crystallisation points of the content to be understood, which gradually gains sense and absorbs all contextual meanings of the text. The key words that are in the centre of the fundamental concepts set the structural and semantic organisation of texts and are related with the peculiarities of the media discourse within which they function.

The formation of intercultural communicative competence through the meaning crystallisation technique takes place both in real and virtual space (Fig. 1).

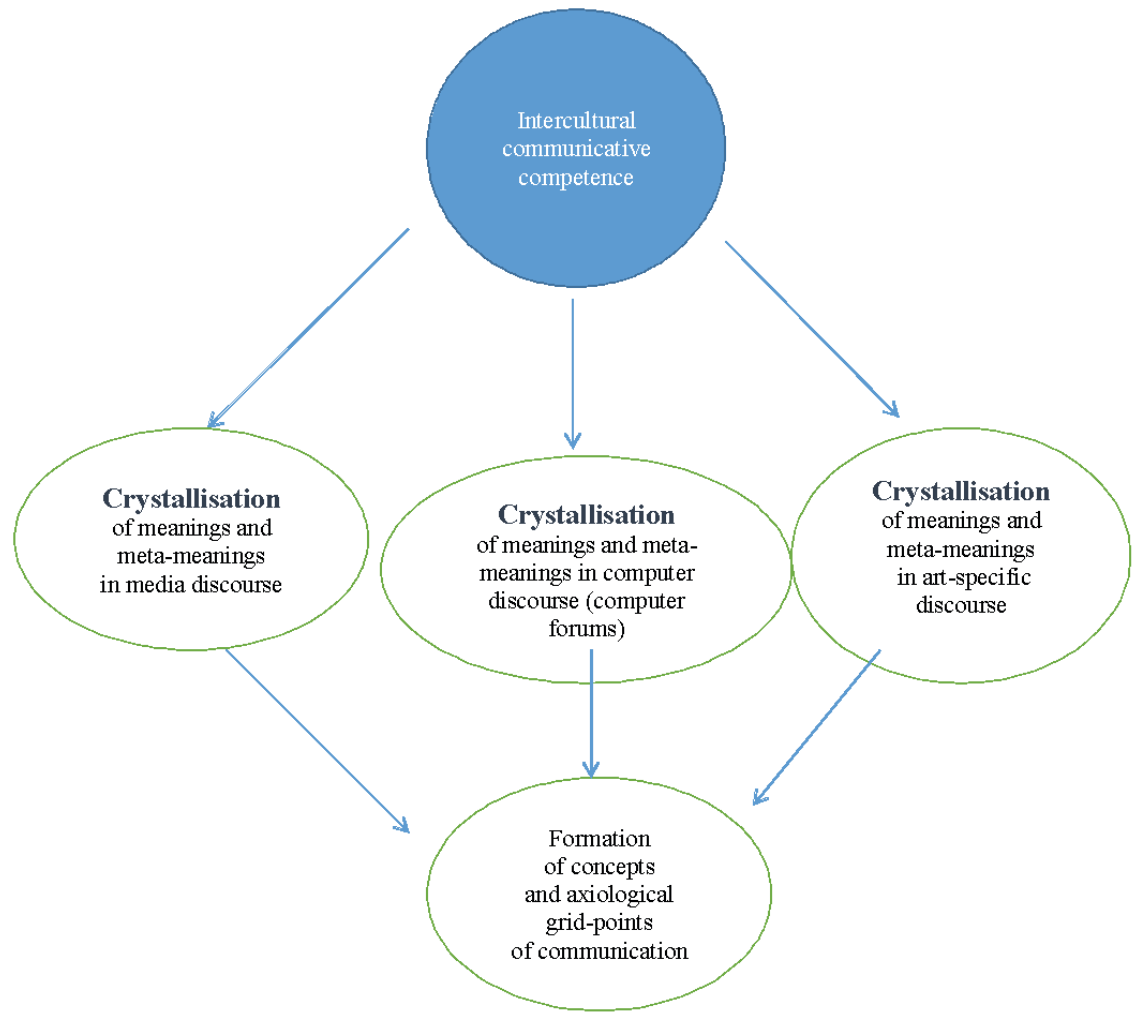

Fig. 1. Scheme of formation of intercultural communicative competence.

In this connection, ideation as a concept plays an essential role, which was repeatedly accentuated by G.Shchedrovitsky [15] and many other researchers. The importance of considering language and ideation as two interconnected and mutually defining systems was stressed by N.Chomsky [23]. V.Zvegintsev asserted that the thought is the basepoint in the dialogue process, being consistent with the language specifics and using words as a means of "active ideation" [14]. The thought and speech, according to the scholar, represent an activity, while the meaning is a certain formation, a result of this activity [14, p. 169]. 
The success of the dialogue "author - recipient" relies on the level of knowledge (both of the author and the reader) about the value priorities of linguocultures, the ways of their conceptualisation and verbalisation.

\section{Conclusion}

Thus, the formation of intercultural communicative competence is the result of a continuous dialogue in which linguistic forms act as a starting point for the process of crystallisation of conceptual substances reflecting the axiological orientations of the society. The totality of meanings reflecting the dialogue of cultures and continuous changes in social relations determines the continuous dynamics of the linguistic and conceptual space that increasingly absorbs new images, senses and meta-meanings.

\section{References}

1. V.P. Litvinov, Polilogotipy: Problemnaya oblast. Pervyi Opyt. Vtoroi Opyt [Polylogos: Problematic Area. First Experience. Second Experience] (Togliatti, 1997) - URL: https://ru.1lib.education/book/3492728/eba058

2. L.X Gao1., L.J. Zhang Teacher Learning in Difficult Times: Examining Foreign Language Teachers' Cognitions About Online Teaching to Tide Over COVID-19. Published: $\quad 15$ September $2020 . \quad-\quad$ URL: https://www.frontiersin.org/articles/10.3389/fpsyg.2020.549653/full

3. M. Gavell Task-Based Reading Activities Using Authentic Materials and Skills // English Teaching Forum 2021, Volume 59, Number 2 - URL: https://americanenglish.state.gov/files/ae/resource_files/etf_59_2_pg02-09.pdf

4. N.Gordon Identifying Narrative Elements in Literature: A Poster Project// English Teaching Forum 2021, Volume 59, Number 1 - URL: https://americanenglish.state.gov/files/ae/resource_files/etf_59_1_pg43-48.pdf

5. K.J.Schmidt, E. Rye Simple English Wikipedia: Free Resources for Beginner to Intermediate Levels // English Teaching Forum 2020, Volume 58, Number 2 URL:

https://americanenglish.state.gov/resources/english-teaching-forum-2020-volume58-number-2

6. M.G.Sergeeva, V.V. Vizaulina, M.M. Kononenko, T.N.Reva, M.M. Kirsanova, S.R. Sadekova, M.A. Berseneva. Creativity of a University Teacher as an Essential Condition for the Professional Development of a Modern Educator // Revista Inclusiones. 2020. T. 7 . № 3. C. 268-279. - URL: https://www.elibrary.ru/item.asp?id=42982798

7. S. Spencer, B.K. Williams B.K., M. Mraz, S. Adrane. Reading Eyes Wide Shut: Visualization, Language Learners, and Texts// English Teaching Forum 2021, Volume $\quad 59, \quad$ Number $\quad 1 \quad-\quad$ URL: https://americanenglish.state.gov/files/ae/resource_files/etf_59_1_pg12-19.pdf

8. L.J. Zhang . Reflections on the pedagogical imports of western practices for professionalizing ESL/EFL writing and writing-teacher education. Austr. Rev. App. Linguist. 2016 39, 203-232. doi: 10.1075/aral.39.3.01zha 
9. T. Th. H. Yen Using Movie Dubbing to Improve Natural English Pronunciation Skills // English Teaching Forum 2021, Volume 59, Number 1 - URL: https://americanenglish.state.gov/files/ae/resource_files/etf_59_1_pg20-25.pdf

10. G.I. Bogin, Obretenije sposobnosty ponimat. Vvedenije $\mathrm{v}$ filologicheskuyu germenevtiku [Gaining the ability to understand: An Introduction to Philological Hermeneutics] (Psychology and Business Online, Moscow, 2021) - URL: https://litgu.ru/knigi/guman_nauki/48547-obretenie-sposobnosti-ponimat-vvedenie -v-filologicheskuyu-germenevtiku.html

11. V.I. Karasik, Yazykovye klyuchi [Language Keys] (Paradigma, Volgograd, 2007) URL: https://www.elibrary.ru/query_results.asp

12. H. Gadamer, Aktualnost prekrasnogo [The Relevance of the Beautiful] (Iskusstvo, Moscow, 1991)

URL: https://platona.net/load/knigi_po_filosofii/fenomenologija/gadamer_g_g_aktualno st_prekrasnogo/53-1-0-1492

13. R. Barthes, Tekstologicheskii analiz [Textual analysis], in New Trends in Foreign Linguistics. Issue IX. Linguostylistics, 307-312 (Progress, Moscow, 1980) Режим доступа: по подписке. https://biblioclub.ru/index.php?page=book\&id=40172

14. V.A. Zvegintsev, Yazyk i lingvisticheskaya teoriya [Language and Linguistic Theory] (Editorial URSS, Moscow, 2001) URL: https://www.ae-lib.org.ua/texts/zvegintsev_language_and_linguistic_theory_ru. htm

15. G.P. Shchedrovitsky, Method Iss, 1-2, 9-12 (1994) . - URL: https://www.fondgp.ru/publications/сладкая-диктатура-мысли/

16. V.I. Karasik, Lingvisticheskaya kristallizatsiya smysla [Linguistic Crystallisation of Meaning] (Paradigm, Volgograd, 2010) - URL: https://www.elibrary.ru/query_results.asp

17. I.P. Cherkasova, Bul Perm Nation Res Polytech Univ. Prob Ling Pedag, 4, 66-76 (2018) DOI: 10.15593/2224-9389/2018.4.6

18. I.P. Cherkasova, Mod Human Success, 4, 179-183 (2020) . - URL: http://mhs-journal.ru/wp-content/uploads/2020/04/mhs_4.pdf

19. I.P. Cherkasova, E.A. Alymova, Bul Perm Nation Res Polytech Univ. Prob Ling Pedag, 1, 35-42 (2020) DOI: 10.15593/2224-9389/2020.1.3

20. I.P. Cherkasova, V.N. Korobchak, L.E.Kuznetsova, S.A Malahova, G.A. Formanyuk Poetic Discours: Text, Hermeneutics, Harmony // Laplage em Revista (International), vol.7, n. 3A, Sept. -Dec. 2021, p.300-308 DOI: https://doi.org/10.24115/S2446-6220202173A1402p.300-308

21. E. Cassirer, An Essay on Man. An Introduction to the Philosophy of Human Culture (Yale University Press, New Haven, 1944) - URL: https://archive.org/details/essayonmanintrod00cass/page/n3/mode/2up

22. Cassirer E. Zur Logik der Kulturwissenschaften. Funf Studien. -Darmstadt: Wissenschaftliche Buchgesellschaft, 1980. 4 unver. Aufl. $|4|+128$ S. . - URL: 
https://www.goodreads.com/book/show/16128051-zur-logik-der-kulturwissenscha ften-f-nf-studien

23. N. Chomsky, Language and Mind (Harcourt Brace Jovanovich Inc., New York, 1968)

URL:

https://www.marxists.org/reference/subject/philosophy/works/us/chomsky.htm 